The Impact of Regional Arctic Sea Ice Loss on Atmospheric Circulation and the NAO

Pedersen, Rasmus A.; Cvijanovic, Ivana; Langen, Peter L.; Vinther, Bo M.

Published in:

Journal of Climate

DOI:

10.1175/JCLI-D-15-0315.1

Publication date:

2016

Document version

Publisher's PDF, also known as Version of record

Citation for published version (APA):

Pedersen, R. A., Cvijanovic, I., Langen, P. L., \& Vinther, B. M. (2016). The Impact of Regional Arctic Sea Ice Loss on Atmospheric Circulation and the NAO. Journal of Climate, 29(2), 889-902. https://doi.org/10.1175/JCLID-15-0315.1 


\title{
¿The Impact of Regional Arctic Sea Ice Loss on Atmospheric Circulation and the NAO
}

\author{
RASMUS A. PEDERSEN \\ Centre for Ice and Climate, Niels Bohr Institute, University of Copenhagen, and Climate and Arctic Research, \\ Danish Meteorological Institute, Copenhagen, Denmark \\ IVANA CVIJANOVIC \\ Atmospheric, Earth, and Energy Division, Lawrence Livermore National Laboratory, Livermore, California
}

Peter L. LANGEN

Climate and Arctic Research, Danish Meteorological Institute, Copenhagen, Denmark

BO M. VINTHER

Centre for Ice and Climate, Niels Bohr Institute, University of Copenhagen, Copenhagen, Denmark

(Manuscript received 30 April 2015, in final form 14 October 2015)

\begin{abstract}
Reduction of the Arctic sea ice cover can affect the atmospheric circulation and thus impact the climate beyond the Arctic. The atmospheric response may, however, vary with the geographical location of sea ice loss. The atmospheric sensitivity to the location of sea ice loss is studied using a general circulation model in a configuration that allows combination of a prescribed sea ice cover and an active mixed layer ocean. This hybrid setup makes it possible to simulate the isolated impact of sea ice loss and provides a more complete response compared to experiments with fixed sea surface temperatures. Three investigated sea ice scenarios with ice loss in different regions all exhibit substantial near-surface warming, which peaks over the area of ice loss. The maximum warming is found during winter, delayed compared to the maximum sea ice reduction. The wintertime response of the midlatitude atmospheric circulation shows a nonuniform sensitivity to the location of sea ice reduction. While all three scenarios exhibit decreased zonal winds related to high-latitude geopotential height increases, the magnitudes and locations of the anomalies vary between the simulations. Investigation of the North Atlantic Oscillation reveals a high sensitivity to the location of the ice loss. The northern center of action exhibits clear shifts in response to the different sea ice reductions. Sea ice loss in the Atlantic and Pacific sectors of the Arctic cause westward and eastward shifts, respectively.
\end{abstract}

\section{Introduction}

The drastic Arctic sea ice decline observed in recent years (Vaughan et al. 2013) has motivated an increased scientific focus on the impacts of sea ice loss on weather and climate. The surface energy balance is affected by sea ice loss through surface albedo

¿ Denotes Open Access content.

Corresponding author address: Rasmus A. Pedersen, Centre for Ice and Climate, Niels Bohr Institute, University of Copenhagen, Juliane Maries Vej 30, DK-2100, Copenhagen, Denmark. E-mail: anker@nbi.ku.dk changes and as a result of a reduction of the insulating layer between the ocean and the atmosphere (Stroeve et al. 2012b). These characteristics mean that sea ice loss initiates feedbacks that contribute directly to Arctic amplification of near-surface warming (Serreze et al. 2009; Screen and Simmonds 2010; Serreze and Barry 2011). Furthermore, Arctic sea ice loss has been linked to climatic changes at lower latitudes through shifts in the oceanic and atmospheric circulation (Bader et al. 2011; Vihma 2014). The remote changes, however, remain challenging to interpret and the mechanisms are still subject to investigation (Francis and Vavrus 2012; Screen and Simmonds 2013; Barnes 2013; Wallace et al. 2014). 
This study investigates the impacts of regional Arctic sea ice loss on high- and midlatitude climate. In an atmospheric general circulation model (GCM) coupled to a slab ocean, we study the atmospheric response to prescribed reductions in the Arctic sea ice cover. In contrast to the slab ocean simulations performed here, most previous studies prescribe both the sea ice and sea surface temperature (SST) (Seierstad and Bader 2009; Deser et al. 2010; Blüthgen et al. 2012; Screen et al. 2013; Peings and Magnusdottir 2014). As discussed by Screen et al. (2013), the atmospheric response in the prescribed SST experiments does not describe the isolated impact of the sea ice change but is a combined response to sea ice and SST change. An advantage of our hybrid setup is that sea surface temperatures are not prescribed; the only forcing is the prescribed sea ice loss. Most importantly, since our slab ocean setup allows for interaction between the atmosphere and the surface ocean (SSTs), we can account for the teleconnections dependent on such an exchange (Chiang and Bitz 2005; Cvijanovic and Chiang 2013).

The atmospheric response to different sea ice configurations has been shown to be sensitive to the geographical location of ice loss (Petoukhov and Semenov 2010; Rinke et al. 2013). We use the new hybrid setup to investigate the atmospheric response to three different sea ice scenarios with ice loss in different parts of the Arctic. Our model simulations are designed to reveal the isolated impact of a changing sea ice cover, as the prescribed sea ice loss is the only forcing in these experiments.

In section 2 we describe the climate model configuration and the experimental design. The results are presented and discussed in section 3, where we assess the impact of the sea ice loss on the Arctic climate, the Northern Hemisphere atmospheric circulation, and the NAO. Conclusions are presented in section 4.

\section{Methods}

\section{a. Climate model configuration}

In this study, we use the National Center for Atmospheric Research's Community Earth System Model (CESM) version 1.0.4 (Gent et al. 2011), which in this setup includes the Community Land Model (CLM4; Lawrence et al. 2011) and the Community Atmosphere Model (CAM4; Neale et al. 2013) coupled to a slab ocean (Danabasoglu and Gent 2009; Neale et al. 2010). The model integrations are performed on a finitevolume $1.9^{\circ} \times 2.5^{\circ}$ grid with 26 atmospheric layers in the vertical. The slab ocean is designed to approximate the behavior of the ocean component of the fully coupled model. Danabasoglu and Gent (2009) compare the slab ocean and the fully coupled configurations of the previous-generation model (CCSM3) and find that the slab ocean setup provides a good estimate of the climate sensitivity of the fully coupled model. The input fields required for slab ocean simulations [prescribed ocean heat flux ( $q$ flux), salinity, temperature, and velocity fields] are derived from a preindustrial CESM simulation using a full-depth ocean. The ocean input fields are identical in all the simulations presented here, and any potential thermohaline or wind-driven ocean heat transport changes are thus disabled (as noted in Caldeira and Cvijanovic 2014).

This model setup is an extension of the prescribed sea ice setup used by Cvijanovic and Caldeira (2015) and Caldeira and Cvijanovic (2014). The new setup combines the two types of simulations used in these studies. The first configuration maintains ice-free conditions by allowing ocean temperatures to drop below freezing without initiating sea ice formation. The second prescribes the sea ice cover, thus preventing sea ice loss in a warming climate, and can be viewed as a hybrid between the slab ocean model (SOM) and the data ocean model (DOM) with interactive sea surface temperatures and fixed sea ice.

In the current setup, we prescribe the sea ice cover to a specified extent while also allowing ocean temperatures to fall below the freezing point $\left(-1.8^{\circ} \mathrm{C}\right)$ in order to prevent new sea ice formation. This combination makes it possible to prescribe any sea ice configuration regardless of the climate state. We allow ocean temperatures below the freezing point in order to prevent an unrealistic increase of the heat flux exchange over icefree areas where new sea ice would form otherwise. Thus our simulations present a more conservative estimate of the forcing from the sea ice loss. The results will reveal that the ice loss still induces a substantial forcing even with subfreezing ocean temperatures allowed.

However, it is useful to note that none of the four simulations presented here have subfreezing sea surface temperatures in pure ocean grid cells (where the sum of land and sea ice fractions is below $1 \%$ ). The lowest temperature found in grid cells with a minimum of $50 \%$ ocean coverage is $262 \mathrm{~K}$. This could be a reasonable average wintertime surface temperature over an area consisting of $50 \%$ sea ice or land and $50 \%$ open ocean near the freezing point.

As our idealized model setup is a simplification of the fully coupled system, it does not describe all the mechanisms of the real-world climate system. While the coupled CESM model in itself has known biases that may affect the simulated response (e.g., excessive low clouds in the Arctic; Gent et al. 2011; Kay et al. 2012), it is important to note the further limitations that arise from our modification of the setup. A noteworthy 


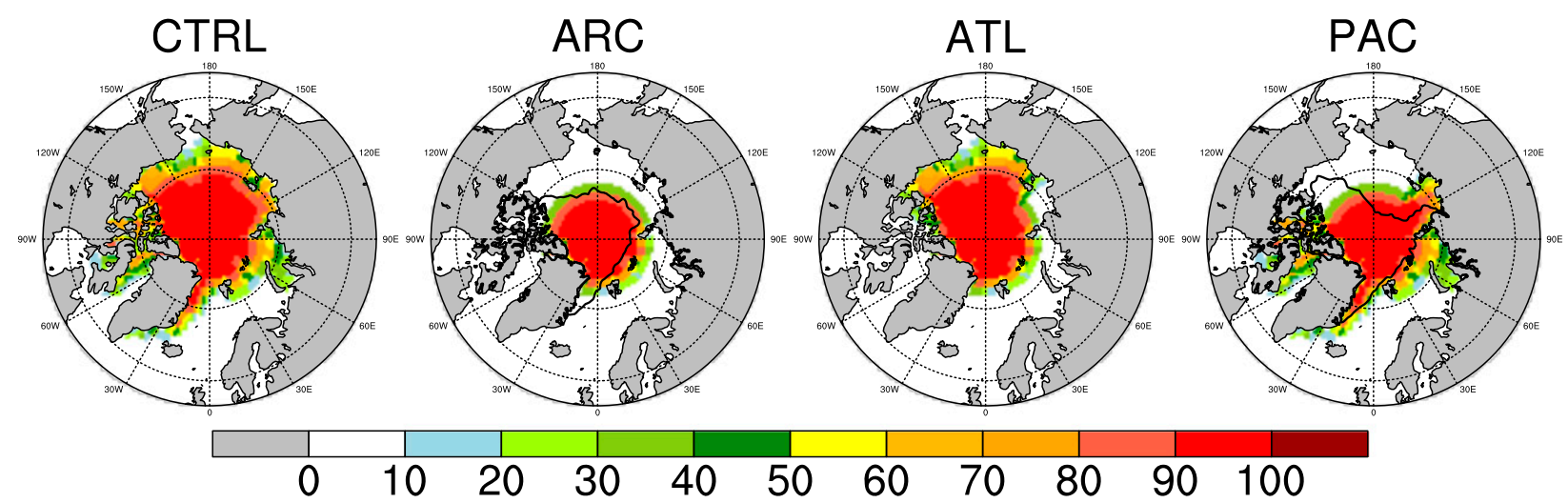

FIG. 1. September sea ice cover (i.e., annual minimum extent; \%) in the four scenarios. Black contours overlaid on ARC and PAC illustrate observed sea ice extent in 2012 and 2007, respectively. The extent is calculated as the $15 \%$ concentration contour in the NOAA/ NSIDC climate data record of passive microwave sea ice concentration (Meier et al. 2013).

shortcoming of the current setup is that the fixed sea ice conditions disable any potential feedbacks from the atmospheric circulation affecting the ice cover. Such feedbacks are known to be important in shaping the Arctic sea ice cover (e.g., by increasing sea ice export from the Arctic; Blüthgen et al. 2012).

\section{b. Experimental setup}

In this study, we analyze the atmospheric response to three idealized sea ice reduction scenarios: sea ice loss over the entire Arctic region and sea ice loss confined to the Atlantic and Pacific sectors of the Arctic. These three scenarios are compared to a preindustrial control state (CTRL), which is also simulated using the prescribed ice, slab ocean configuration. The prescribed CTRL sea ice conditions are obtained from a coupled CESM preindustrial simulation with a full-depth ocean.

The first scenario represents a reduction of the Arctic sea ice cover across all longitudes (hereafter referred to as the ARC scenario). The annual minimum September sea ice extent is constructed by removing all sea ice south of $78^{\circ} \mathrm{N}$ from the CTRL September extent. To avoid unnatural steep gradients in the sea ice cover, the ice concentrations are smoothed near the new, constructed ice edges. The areas in the two southernmost grid cells along the new ice edge have been reduced to $33 \%$ and $66 \%$, respectively, of the control climate ice concentration across all longitudes. The resulting ice cover is shown in Fig. 1.

Based on the CTRL and ARC configurations, two additional sea ice scenarios are constructed to study the atmospheric response to sea ice loss in different geographical regions. Starting from the annual minimum sea ice extent in September, the overall reduction in ARC is split in two regions, referred to as the Atlantic (ATL) and Pacific (PAC) sectors. The two sectors are chosen so that the area of sea ice removed is identical in the two scenarios and that the area of sea ice removed in the two sectors sum exactly to the ARC sea ice loss. To, once again, avoid steep gradients near the ice edges, the regions are defined with a $5^{\circ}$ longitudinal overlap, where the sea ice in both cases is set to $50 \%$ of the CTRL concentration. The boundaries between ATL and PAC are at $110^{\circ} \mathrm{W}$ (overlap from $110^{\circ}$ to $115^{\circ} \mathrm{W}$ ) and $140^{\circ} \mathrm{E}$ (overlap from $140^{\circ}$ to $145^{\circ} \mathrm{E}$ ). Thus, the Atlantic sector includes the Baffin Bay and the Greenland, Barents, Kara, and Laptev Seas, while the Pacific sector covers the Beaufort, Chukchi, and East Siberian Seas. Figure 1 displays the September sea ice cover in all four simulations (CTRL, ARC, ATL, and PAC).

In the design of the Atlantic and Pacific sectors, we have aimed to balance the magnitude of forcing from the sea ice loss in the two sectors. Hence, equal amounts of sea ice area (i.e., sea ice concentration multiplied by the gridcell area) are removed in the two sectors. A consequence of this design is that the Atlantic and Pacific sectors do not cover equal geographical areas. An alternative approach would be to divide the Arctic region in two equal sectors in terms of geographical coverage. In that case, the area of sea ice removed, and thereby the induced forcing, would be substantially larger in the Pacific compared to the Atlantic sector. Therefore, the difference between the atmospheric responses in the two scenarios might be governed by the different magnitude of forcing rather than the location of the ice loss.

The geometry of the idealized sea ice cover is based on the assumption that the sea ice in the central Arctic will be more persistent in a warming climate [as illustrated by Stroeve et al. (2012b) for the period from 1979 to 2010]. The prescribed ice extents resemble the observed conditions as seen from Fig. 1 where the ARC and PAC sea ice fields have been overlaid with observed sea ice 


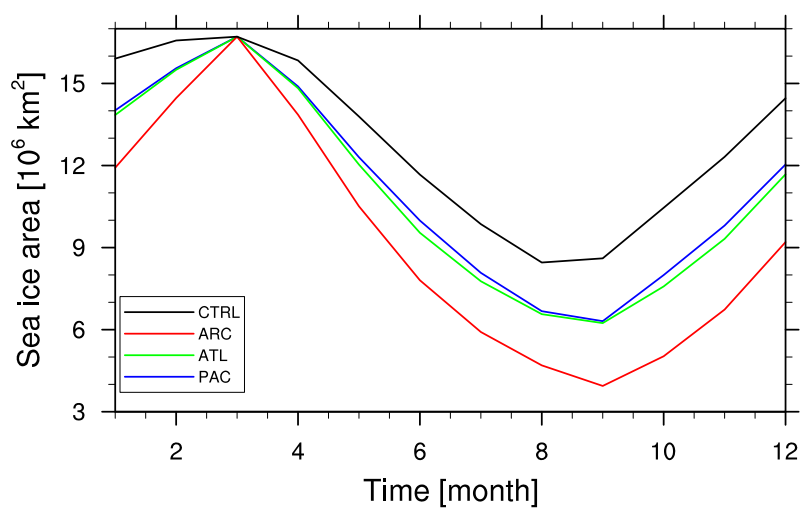

FIG. 2. Annual cycle of Northern Hemisphere sea ice area $\left(10^{6} \mathrm{~km}^{2}\right)$ in the four simulations: CTRL (black), ARC (red), ATL (green), and PAC (blue).

extents from 2012 and 2007, respectively (observations from NOAA/NSIDC climate data record of passive microwave sea ice concentration; Meier et al. 2013).

Motivated by observational trends that show that the annual maximum sea ice extent exhibits a limited decrease compared to the annual minimum extent (Stroeve et al. 2012a), the March sea ice is left unchanged from the CTRL. The sea ice concentrations in all other months are constructed from monthly weighted means between the new reduced September conditions and the concentrations from the control climate in the given month (the annual cycle of total sea ice area is presented in Fig. 2). Compared to the control climate, the imposed sea ice area changes result in a year-round sea ice reduction, increasing from no change in March to maximum change in September. Figure 3 displays the seasonal mean sea ice reduction in ARC compared to CTRL, with the boundaries of the two regional scenarios depicted by colored boxes. All the simulations are identical except for the Arctic sea ice cover. Sea ice thickness is fixed ( $1 \mathrm{~m}$ in the Northern Hemisphere and $2 \mathrm{~m}$ in the Southern Hemisphere), and the atmospheric conditions are kept at the preindustrial level.

Anomalies presented in the remaining text are based on climatological means over the last 30 years of the model simulations. The climatologies are based on monthly mean data. The total length of each simulation is 60 years, with the first 30 years disregarded as spinup. Statistical significance of changes is assessed using a twosided Student's $t$ test (von Storch and Zwiers 2001).

\section{Results and discussion}

\section{a. Arctic response and local changes}

The imposed sea ice loss causes vast changes in the Arctic climate in our model simulations. Across all three scenarios, the surface-based changes in sea ice cause a geographically widespread warming in the near-surface air temperature throughout the year (displayed in Fig. 4).

The peak warming is more than $15 \mathrm{~K}$ and coincides geographically with the ice loss area. The maximum warming is found in the winter season (DJF) in all three scenarios. This might appear surprising, as the maximum sea ice loss is introduced in September. The reason for this delayed response is found in the physical mechanisms behind the warming. Sea ice loss affects the surface energy fluxes by altering the shortwave, longwave, and turbulent heat (latent and sensible heat) fluxes at the ocean surface. Figure 5 shows the annual cycle of the Arctic mean surface turbulent heat and net energy flux changes and reveals that the wintertime warming is driven mainly by turbulent heat flux from the ocean surface. Even though the ice cover is partially restored during winter, the insulating effect of the sea ice is reduced and increasing amounts of heat and moisture can

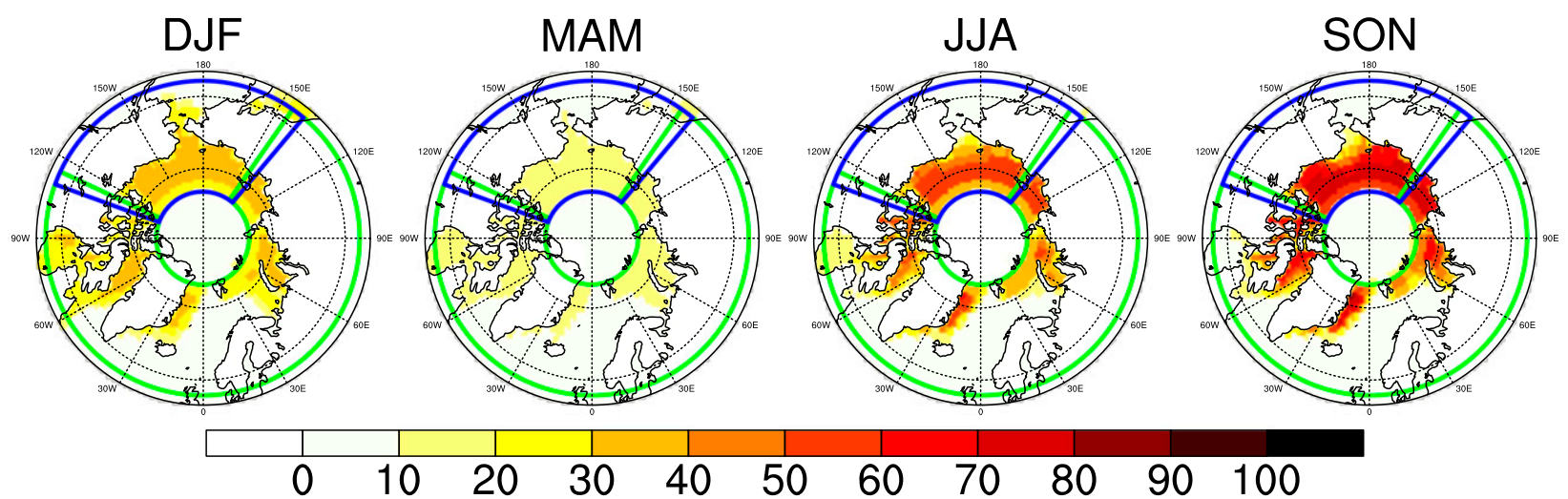

FIG. 3. Seasonal mean anomalies in sea ice concentration (\%) between the reduction scenarios and the preindustrial CTRL. PAC is bounded by the blue line, ATL by the green line, and ARC is across all longitudes. 

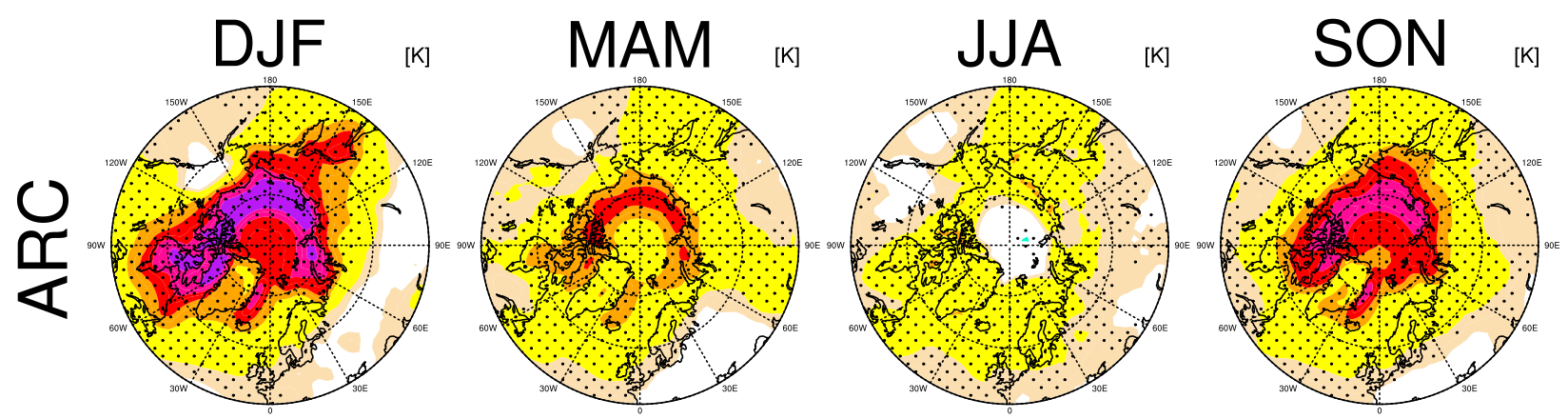

[K]

[K]

$[\mathrm{K}]$

$[\mathrm{K}]$
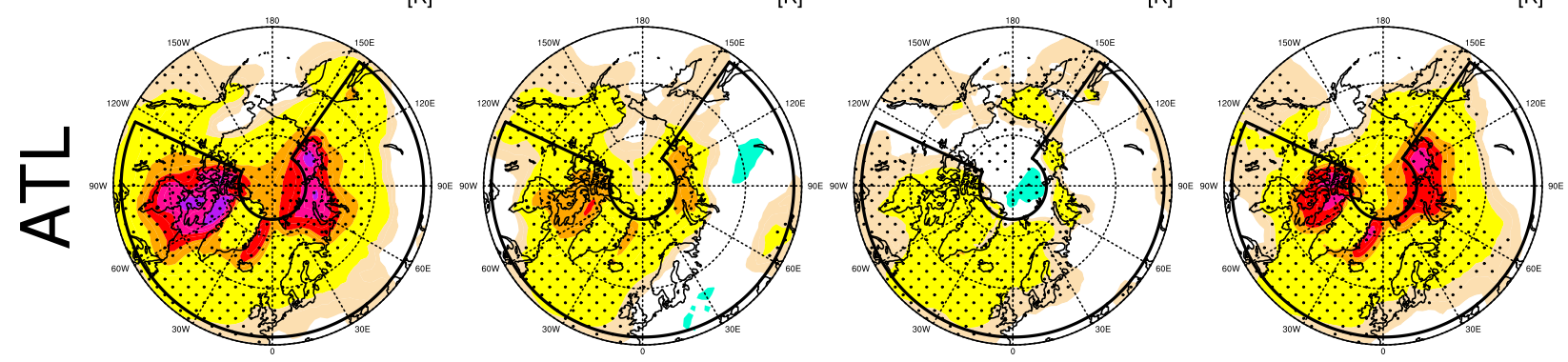

$[\mathrm{K}]$

$[\mathrm{K}]$

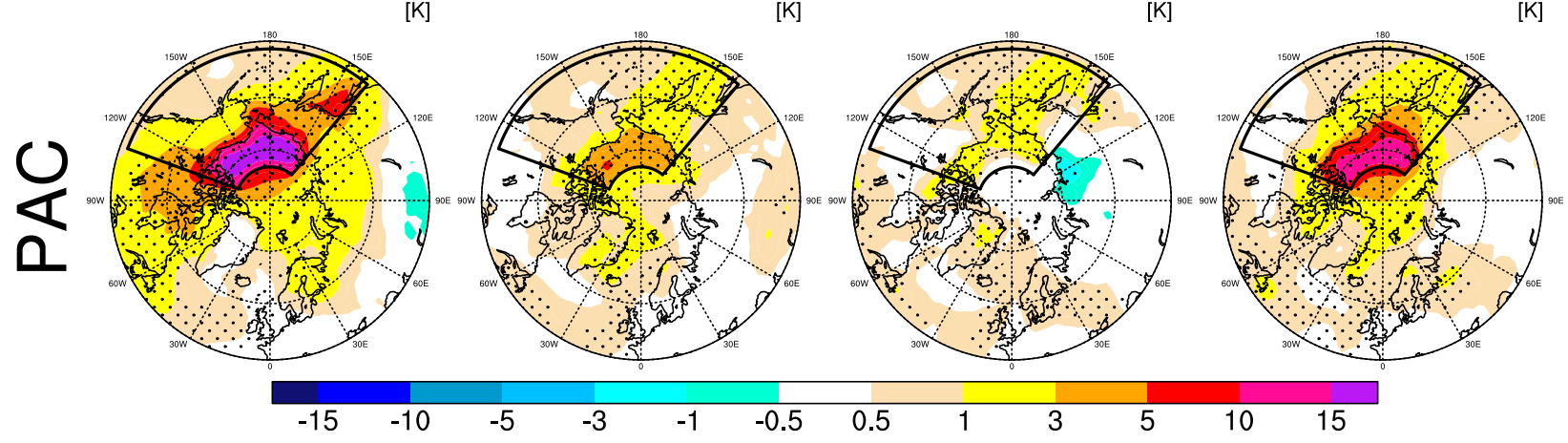

FIG. 4. Seasonal mean near-surface air temperature change (K) compared to the CTRL. Black boxes indicate regions of sea ice loss; (top) ARC is reduced at all longitudes. Black dotted areas indicate statistical significance at the $95 \%$ confidence level. Note the irregular spacing of the color bar.

be exchanged between the ocean and atmosphere. The insulation between the ocean and atmosphere is only weakened as a result of reductions in the sea ice concentration, as the ice thickness is fixed in our experiments. The upward heat flux is driven by the large wintertime temperature gradient between ocean and atmosphere, which persists in our experiments, although the SST is allowed to cool below freezing. This key role of the turbulent heat flux and the related delayed warming agrees with several other studies of sea ice loss (Deser et al. 2010; Screen et al. 2013; Vihma 2014).

Increased longwave loss from the surface also contributes to the surface-based warming, but the longwave flux change amounts to only one-third of the turbulent changes during winter (cf. the net and the turbulent heat fluxes in Fig. 5). The shortwave flux does not contribute directly to the atmospheric warming but may have an indirect impact by causing additional ocean warming in regions of ice loss. Increased shortwave absorption contributes to the negative net surface flux during summer, as evident in Fig. 5.

The temperature response resembles the spatial pattern of the sea ice loss (cf. Figs. 3 and 4). This is likely connected to a limited vertical extent of the warming (not shown), owing to a very stable structure of the lower atmosphere. Low-level stability with frequent surface-based inversions is a well-known feature in the Arctic seen in both observations and climate models (Zhang et al. 2011). Climate models, including the one employed here, even have a tendency to overestimate the stability during the polar night (Boé et al. 2009; Barton et al. 2014). Our simulations show that the 


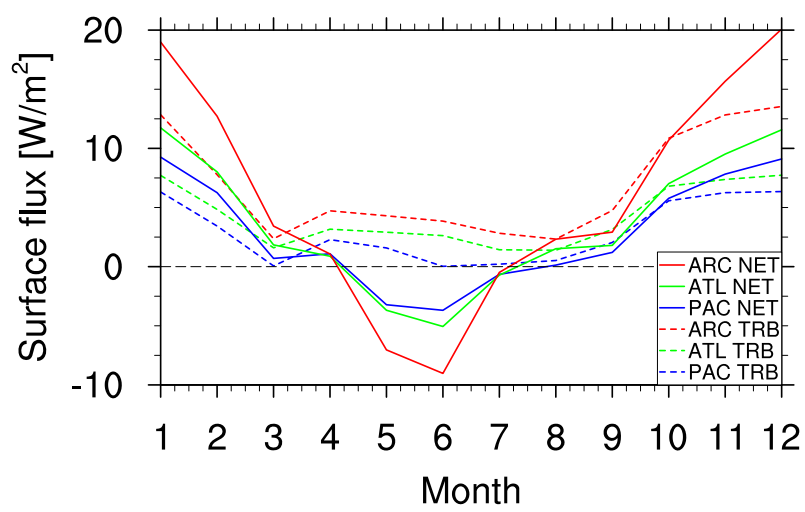

FIG. 5. Seasonal cycles of Arctic $\left(60^{\circ}-90^{\circ} \mathrm{N}\right)$ monthly mean surface flux anomalies $\left(\mathrm{W} \mathrm{m}^{-2}\right)$ in the three scenarios compared to CTRL: ARC in red, ATL in green, and PAC in blue. The net flux (NET; solid lines) is the sum of the shortwave, longwave, sensible heat, and latent heat surface fluxes, and the turbulent heat flux (TRB; dashed lines) is the sum of the sensible and latent heat surface fluxes. Positive values indicate flux upward from the surface to the atmosphere.

surface-based warming will gradually work to weaken the stability but that the inversion structure persists over the remaining sea ice cover even with the substantial warming simulated here.

An interesting feature in the warming pattern (Fig. 4) is the warming over the Greenland ice sheet (GIS). Sea ice changes in the vicinity of Greenland are expected to cause warming over the ice sheet through atmospheric heat advection. Accordingly, significant warming signals are evident over GIS in both ARC and ATL. In contrast, the more remote sea ice loss in the Pacific region only seems to cause a limited or insignificant Greenland warming signal. This indicates that sea ice loss distant from the GIS (such as the minimum extent observed in 2007) does not have a substantial impact on the temperatures over the ice sheet. This finding is relevant to projections of GIS melt in a warmer climate (i.e., simulations of future-climate as well as paleoclimate scenarios).

\section{b. Remote response and circulation changes}

Despite the fact that the sea ice forcing is largest in the autumn, the near-surface warming peaks during winter. This could indicate that the atmosphere experiences the largest forcing during winter rather than autumn. However, it is not certain that the strongest response of the atmospheric circulation coincides with the maximum near-surface temperature change. Thus, the fall [September-November (SON)] seasonal mean and the monthly progression of the atmospheric circulation response have been examined (not shown). While it might not be linked directly to the near-surface temperature response, we find that the circulation response is indeed strongest during winter (the three variables considered here are geopotential height, zonal wind, and transient eddy kinetic energy). The fall patterns exhibit some significant changes, but compared to the winter patterns the changes are of lower magnitude and less widespread significance.

The monthly data reveal that the changes in the individual months are roughly similar to the seasonal means. The strongest circulation responses are found between November and February, but we find no clear pattern in the timing of the strongest changes. The timing varies between both the experiments and the individual circulation parameters (i.e., geopotential height, zonal wind, and transient eddy kinetic energy).

As our simulations exhibit the strongest response to the sea ice loss during winter; the remainder of this analysis will focus on the wintertime [DecemberFebruary (DJF)] seasonal mean changes.

The temperature anomalies in Fig. 4 show substantial warming outside the regions of ice loss. Warming in the vicinity of the ice loss is an expected result of heat advection from the newly ice-free regions (Serreze et al. 2011). Warming in more distant areas, however, could be related to changes in the atmospheric circulation rather than direct advection from the heat source. One asset of our hybrid setup is exactly that it allows these remote changes. An alternative setup with fixed SSTs would inhibit remote changes over ocean surfaces and potentially limit or completely disable important feedbacks and teleconnections.

Previous studies have indeed indicated that the largescale circulation could be affected by sea ice loss (Bader et al. 2011; Vihma 2014). Depending on the mechanisms behind potential remote changes, the different sea ice scenarios simulated here may lead to different circulation shifts. To examine such changes, a range of atmospheric properties are investigated in the following (see Fig. 6).

The geopotential height of the 500-hPa pressure surface increases at high latitudes across all three scenarios (Fig. 6, top). This is an expected result of the surfacebased warming, which works to expand the overlying air masses. In the ARC scenario, the increase is statistically significant in an area covering the entire Arctic region toward the midlatitudes. In the ATL and PAC scenarios, the maximum increase is found in the vicinity of the ice loss regions. Significant increases are, nonetheless, also found in smaller areas more remote to the sea ice loss in both scenarios. All three simulations show increased geopotential height over the Labrador Sea, parts of northern Europe, and parts of northeast Asia. Similar increases appear in ARC and ATL over northwest Asia, while no significant signal is found in PAC. Most of 

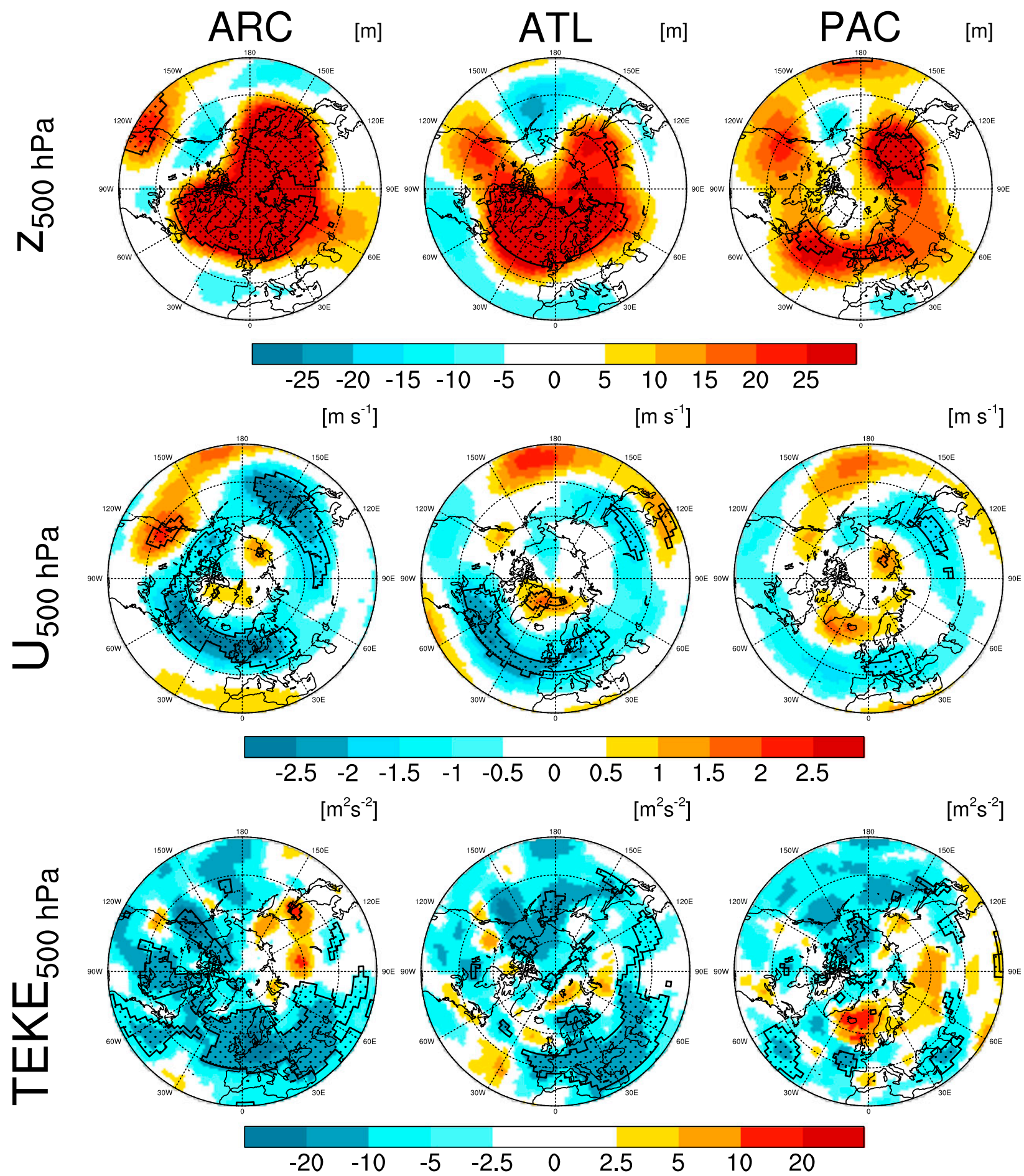

FIG. 6. DJF atmospheric circulation anomalies in the three scenarios - (left) ARC, (middle) ATL, and (right) PAC - compared to CTRL: (top) the geopotential height of the 500-hPa surface, (middle) zonal wind speed, and (bottom) TEKE. All three parameters are shown at the 500-hPa level. Dotted areas indicate that the anomalies are statistically significant at the $95 \%$ confidence level. Note the irregular spacing of the TEKE color bar.

the significant increase is found over or adjacent to areas with strong surface-based warming. This agrees with the general expectation of geopotential height increases in warming regions, but especially the PAC response indicates that strong near-surface warming can occur without increased geopotential height directly above.

The general reduction of the equator-to-pole temperature gradient is manifested in the geopotential height, 
where the meridional gradient is also reduced. This is expected to have implications for the midlatitude atmospheric circulation (Francis and Vavrus 2012; Peings and Magnusdottir 2014). Following the thermal wind relation, the midtropospheric zonal flow is expected to weaken with a decrease of north-south gradient of the 500-hPa geopotential height (i.e., the thickness of the 1000-500-hPa layer). Figure 6 (middle) reveals that the midlatitude flow is indeed reduced in all three scenarios-albeit more widespread in ATL and especially ARC compared to PAC. As expected from the thermal wind relation, the zonal wind reduction appears to agree well with the geopotential height changes. Areas of significant zonal wind reduction appear south of regions with geopotential height increases in all three scenarios.

All three ice loss patterns result in a reduced flow over East Asian midlatitudes and parts of central Europe. The overall ice loss in ARC causes significant reductions in a wide midlatitude band across the North Atlantic, Europe, East Asia, the west Pacific, and northern North America. The ATL response shows a comparable, overlapping reduction, but the ATL pattern appears to be shifted slightly southward. The only significant PAC responses are found over East Asia and central Europe, where zonal wind reduction is found (in agreement with ARC and ATL). No significant changes are evident over the Atlantic midlatitude region, where decreasing flow is observed in the two other scenarios.

A third indicator of atmospheric circulation changes is the transient eddy kinetic energy (TEKE), which is a measure of variability of the wind field. Following Peixóto and Oort (1984), TEKE is calculated from zonal and meridional wind components $U$ and $V$ as follows:

$$
\mathrm{TEKE}=\overline{U^{\prime 2}}+\overline{V^{\prime 2}}
$$

where the overbar denotes time averaging, and the primes denote the departure from the mean as $U=\bar{U}+U^{\prime}$. The TEKE can be used as an indicator of the locations and strengths of weather systems (transient eddies) and thus the mean storm tracks (Hurrell et al. 1998; Sewall 2005; Greeves et al. 2007; Seierstad and Bader 2009; Li and Battisti 2008). The TEKE can be computed from the model wind output as follows:

$$
\begin{aligned}
\mathrm{TEKE} & =\overline{U^{\prime 2}}+\overline{V^{\prime 2}}=\left(\overline{U^{2}}-\bar{U}^{2}\right)+\left(\overline{V^{2}}-\bar{V}^{2}\right) \\
& =\overline{U U}+\overline{V V}-\bar{U}^{2}-\bar{V}^{2} .
\end{aligned}
$$

The monthly mean value of the four latter variables are used to calculate the wintertime (DJF) seasonal mean of TEKE presented and analyzed here.
Reduced TEKE over the midlatitudes appears as the dominant signal. The ARC scenario shows the strongest trend in the TEKE (Fig. 6, bottom), which is reduced across the midlatitudes ranging from North America eastward to Europe and western Asia. The Pacific Ocean, central Asia, and East Asia only exhibit smaller areas of significant changes. A small area over the East Asian midlatitudes exhibits the only significant TEKE increase.

The ATL scenario shows a comparable TEKE reduction, while the only widespread significant area is found over Europe and western Asia. Additionally, areas of significant decrease are evident over the Beaufort and Bering Seas.

The PAC ice loss causes a similar significant TEKE reduction near the Beaufort Sea, while the midlatitude changes are more sparse and scattered compared to ARC and ATL. The PAC scenario exhibits significant reductions over the central Atlantic Ocean (in the southernmost part of Fig. 6, bottom) and parts of the Middle East. A small region in the eastern Atlantic near the west coast of Europe agrees with the TEKE reduction in the two other scenarios, but otherwise there are no significant TEKE changes over continental Europe.

While the geopotential height and zonal wind changes over East Asia revealed reasonable agreement between the three scenarios, the TEKE shows some contrasting changes. PAC and ATL both show smaller areas of TEKE decrease of significant, but limited, magnitude over East Asian midlatitudes. In comparison, ARC exhibits a region of increased TEKE near the coast. This may indicate nonlinearity in the circulation response; the forcing in the ATL and PAC scenarios favor similar changes, but the combination of the two favors a different response.

It has been suggested that sea ice loss could lead to more persistent midlatitude weather through zonal wind reduction and increased meandering of the planetary waves (Francis and Vavrus 2012). These findings regarding midlatitude weather patterns are, however, subject to ongoing scientific debate (Screen and Simmonds 2013; Barnes 2013; Wallace et al. 2014).

Generally, our analysis of the atmospheric circulation does suggest a link between Arctic sea ice loss and midlatitude weather. Significant midlatitude reductions of zonal wind and TEKE are found in all three scenarios, albeit in varying regions and extent. The TEKE anomalies indicate a reduced variability of the midlatitude winds that would be consistent with weakening or less frequent passage of the weather systems. While our analysis cannot reveal the mechanism behind the changes, the TEKE results could lend support to the 
idea of more persistent midlatitude weather (as suggested by Francis and Vavrus 2012).

Several studies have identified links between Arctic sea ice loss, circulation changes, and cold winters in Europe and parts of Asia (Petoukhov and Semenov 2010; Yang and Christensen 2012; Cohen et al. 2013; Peings and Magnusdottir 2014; Tang et al. 2013). Nevertheless, none of the three sea ice reduction scenarios result in colder winters in Europe or Asia (cf. Fig. 4). Outten and Esau (2012) propose that the continental cooling is linked to a reduced meridional temperature gradient and the consequent reduction of the zonal wind. These conditions are apparent in multiple regions over Europe and Asia in all three simulations, but neither response shows significant cooling in these regions (cf. Figs. 4 and 6). There are two potential explanations for this lack of cooling in our experiments. It could indicate a nonlinear nature of the atmospheric response to sea ice loss. Several studies suggest that a sea ice decline exceeding the current observations no longer favors the colder winter conditions (Petoukhov and Semenov 2010; Yang and Christensen 2012; Peings and Magnusdottir 2014). The sea ice loss applied here is relatively strong and widespread and could be too extensive to cause the cold Eurasian winters. Alternatively, this particular model might not favor the circulation changes that cause the colder winters.

We will further investigate the circulation changes by examining the North Atlantic Oscillation (NAO). The NAO describes the leading mode of atmospheric variability in the North Atlantic region and is closely related to circulation changes affecting the wintertime climate of Eurasia and the Arctic (Hurrell 1995; Wanner et al. 2001; Hurrell et al. 2003; Hurrell and Deser 2010; Bader et al. 2011).

\section{c. $N A O$}

The link between the NAO and sea ice cover has been investigated by several other studies (Magnusdottir et al. 2004; Deser et al. 2004; Kvamstø et al. 2004; Seierstad and Bader 2009; Strong and Magnusdottir 2011; Jaiser et al. 2012; Peings and Magnusdottir 2014). Despite varying conclusions, there seems to be widespread agreement that Arctic sea ice loss favors the negative mode of the NAO (Vihma 2014). In our experiments, the NAO index shows no significantly different response to the varying patterns of sea ice loss (not shown), but further analysis reveals that the circulation pattern is indeed affected.

Empirical orthogonal function (EOF) analysis has been performed for the North Atlantic region in order to assess the circulation changes in more detail. The leading mode of variability in the sea level pressure (i.e., the first EOF) is a representation of the NAO (Kutzbach 1970; Deser 2000; Hurrell et al. 2003). The analyzed region covers $20^{\circ}-80^{\circ} \mathrm{N}$ and $90^{\circ} \mathrm{W}-40^{\circ} \mathrm{E}$ (following Hurrell 1995; Hurrell et al. 2015), and the analysis is based on sea level pressure weighted by the square root of cosine of the latitude. The first EOF, presented in Fig. 7, reveals that the NAO is the dominant mode of variability in all simulations. The NAO describes similar fractions of the variability in all four simulations: $45.8 \%, 55.9 \%, 43.4 \%$, and $42.7 \%$, respectively, in CTRL, ARC, ATL, and PAC. The spatial pattern, however, reveals a difference in response to the varying sea ice reductions.

While the leading EOFs in the four simulations all are similar to the observed NAO pattern, the shape and position of the two extremes appear to shift with the different sea ice reductions. The location of the two extremes of the EOF can be interpreted as "centers of action," representing the mean locations of the Icelandic low and Azores high that form the NAO pattern in terms of sea level pressure. To visualize the potential shift, the locations of the centers of action are marked in Fig. 7: The grid cells with the ten highest and ten lowest values in the region are marked with white dots to illustrate the locations of the maximum (the Azores high) and the minimum (Icelandic low).

To further investigate the robustness of this shift, we employ a bootstrap analysis (Efron and Gong 1983; von Storch and Zwiers 2001) where a resampling procedure presents an estimate of the variance in the dataset based on a large number of random subsets from the dataset. Similarly to the approach from Wang et al. (2014), a total of 500 random 30-yr samples are drawn with replacement from the 30 years that form the analyzed climatology. Based on each 30-yr sample, we conduct a new identical EOF analysis and calculate the location of the centers of action. The centers of action from the bootstrap analysis are presented in Fig. 8. As in Fig. 7, the ten highest and lowest values from each sample are used to assess the locations of the minimum and maximum. This assures more robust distributions compared to only selecting one maximum and one minimum location from each sample.

The bootstrap analysis reveals some variance in the location of the centers of action. Nevertheless, the location of the northern center of action appears sensitive to the location of sea ice loss, and some clear groupings appear for each of the simulations. The overall tendency is that the CTRL centers group near the Icelandic east coast, the ARC ice reduction shifts the grouping eastward, the PAC ice reduction shifts even farther eastward, and the ATL reduction triggers an opposite shift westward from the CTRL grouping. The southern 
CTRL

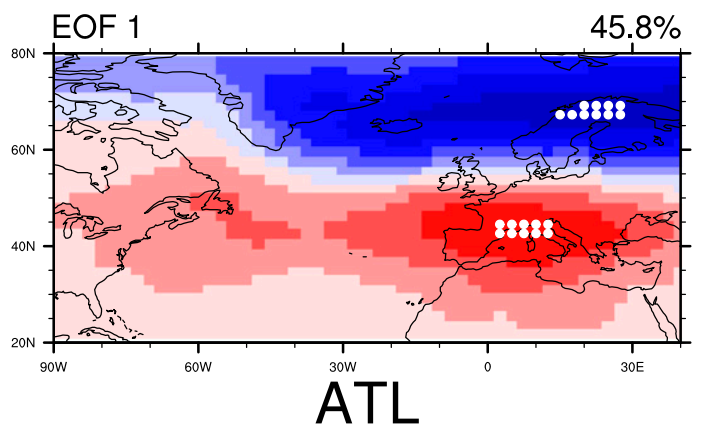

ATL

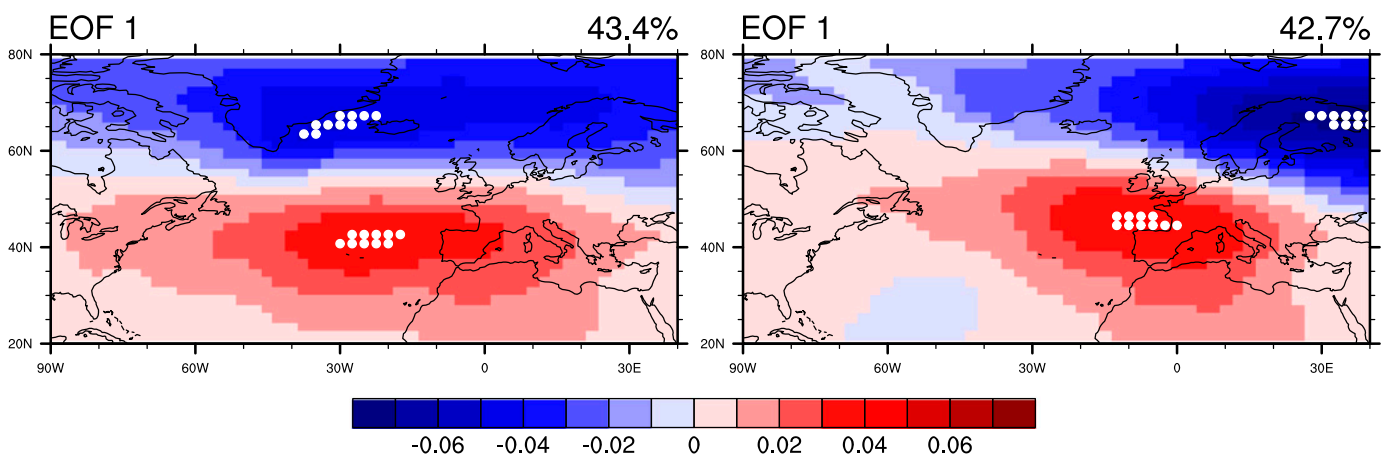

FIG. 7. The first EOF of the DJF mean weighted sea level pressure in the four simulations. The weight on the particular mode of variability is shown in the top right corner of each plot. White circles mark the location of the 10 highest and lowest values, thus indicating the locations of the NAO centers of action. center shows no similar clear shifts or groupings; most of the locations are clustered around $40^{\circ} \mathrm{N}, 0^{\circ} \mathrm{E}$. The ATL westward shift and the PAC eastward shift are both of $20^{\circ}-30^{\circ}$ longitude (cf. Fig. 8). The combined ARC reduction caused a less pronounced eastward shift-reminiscent of a linear combination of the ATL and PAC shifts. This is one of the few examples that suggest any kind of quasi-linear responses, when comparing the sum of ATL and PAC to ARC.

As described by Wang et al. (2014), bootstrap analysis is an advantageous method to assess the spatial variability of the EOF-based NAO pattern and can illustrate the uncertainty of the location of the NAO centers. Hence, our Fig. 8 provides more information on the spatial changes of the NAO pattern compared to Fig. 7. The bootstrap reveals that some of the center locations found based on the single EOF in Fig. 7 are not representative of the complete dataset. Notable differences are seen in the locations of the northern center in the CTRL experiment and the southern center in the ATL.

Shifts in the location of the NAO centers of action are known from several other studies. An eastward shift has been identified in observations from the late 1970s (Hilmer and Jung 2000; Jung et al. 2003; Dong et al. 2011) and in climate modeling studies of increasing greenhouse gas scenarios (Ulbrich and Christoph 1999; Hu and Wu 2004; Dong et al. 2011). Recently, Wang et al. (2014) also identified this significant eastward shift using bootstrap analysis of reanalysis data.

Using GCM simulations, Ulbrich and Christoph (1999) found a shift in the NAO pattern, which was not captured by the NAO index. The simulations were forced with increasing greenhouse gas concentrations, and the authors identified increased storm-track activity in combination with a northeastward shift of the NAO northern center of action. Their preindustrial control climate and years with low forcing had the northern center of action located at the Greenlandic southeastern coast, while it shifted into the Nordic seas (northeast of Iceland) when the forcing exceeded $3 \mathrm{~W} \mathrm{~m}^{-2}$. The shift was accompanied by an increase of the westerlies in the North Atlantic region. This corresponds well to the results of the PAC scenario here, where the eastward shift is accompanied by zonal wind increase over the North Atlantic (the wind speed increase here is, however, statistically insignificant). Ulbrich and Christoph (1999) conclude that the reason for the observed shift "remains 


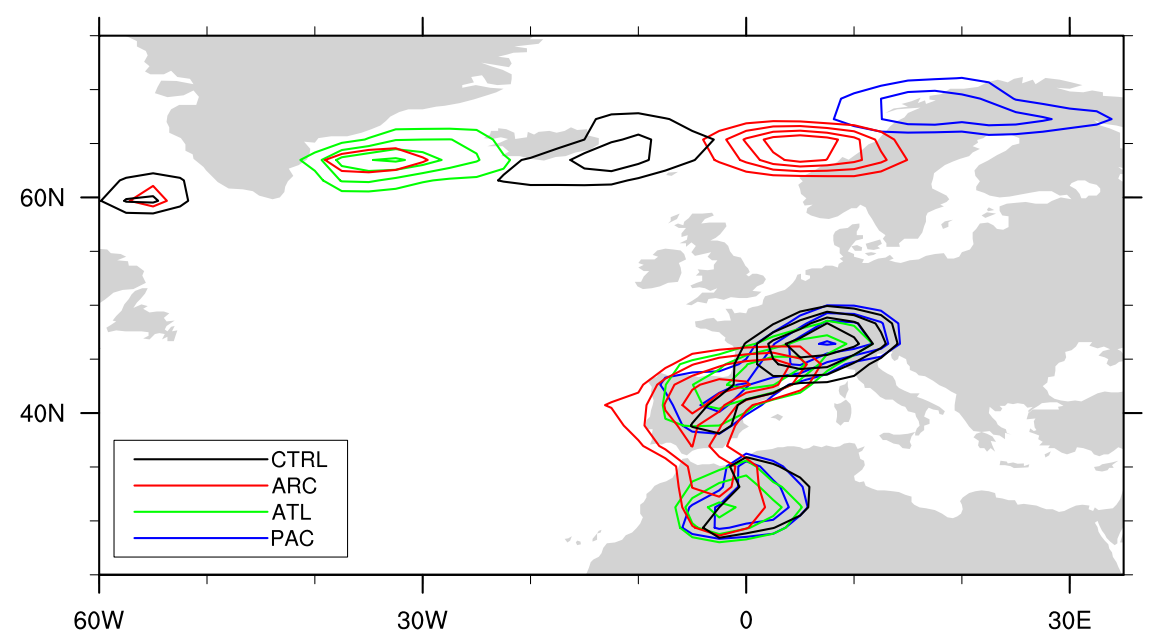

FIG. 8. The location of the DJF NAO centers of action are illustrated through the location of the ten highest and ten lowest values of the leading EOF from each bootstrap sample. Contours show the total number of occurrences in each grid cell combining all 500 samples: CTRL in black, ARC in red, ATL in green, and PAC in blue. The contour interval is 50 counts with the lowest contour at 50 . Only a subset of the analyzed region is displayed; spurious counts over the Great Lakes in North America are not shown.

an open question," and unfortunately there is no mention of sea ice changes or surface-warming patterns in the paper.

Dong et al. (2011) identify a similar eastward shift of the NAO centers of action in both observations and a series of AGCM experiments with increased $\mathrm{CO}_{2}$ and SST. While the eastward shift is similar to the response in our PAC ice loss simulation, the simulations by Dong et al. (2011) exhibit significant Arctic warming only near the Barents Sea, indicating that this is also the only region with a chance of substantial sea ice loss.

Peterson et al. (2003) investigated the mechanism of the pattern shift by performing experiments with a primitive equation atmospheric model. Their results revealed a nonlinear dependence of the spatial pattern of the NAO on the NAO index. They found an eastward (westward) shift in connection with high (low) NAO indices. Our results do, however, indicate that such shifts can occur even without a clear trend in the NAO index.

\section{Conclusions}

All of the three idealized sea ice loss scenarios (ice loss in the entire Arctic and in the Atlantic and Pacific sectors only) result in substantial wintertime warming. The warming is driven by turbulent heat fluxes from the newly ice-free ocean and is to a large extent confined to the region of sea ice loss. The Arctic region exhibits an overall warming in all three scenarios, but ice loss in the Pacific sector of the Arctic (such as the observed extent in 2007) causes only limited warming over the Greenland ice sheet.

The simulations show that the midlatitude atmospheric circulation is affected by sea ice loss. All three simulations show increased geopotential height at high latitudes near the regions of sea ice loss. There is, however, no direct overlap between the spatial patterns of near-surface warming and geopotential height at the 500-hPa level; substantial surface-based warming can occur without a significant increase of the geopotential height directly above. As expected from the thermal wind relation, the decreased meridional gradient in geopotential height causes a general reduction in zonal wind strength. Significant wind reductions are found south of areas of increased geopotential heights in all experiments. The three ice loss scenarios all cause reduced midlatitude zonal winds over Europe and East Asia. Substantial midlatitude wind reductions are found over the Atlantic Ocean in both ARC and ATL, while no significant changes are evident in PAC. The circulation patterns indicate a nonuniform atmospheric sensitivity to the location of ice loss. While some regions show a similar atmospheric response to the different scenarios (e.g., decreased zonal flow over central Europe and East Asian midlatitudes), it is clear that other regions are sensitive to the location of the sea ice loss. The North Atlantic Oscillation in particular exhibits a high sensitivity.

This study, in line with several previous studies, demonstrates a link between the Arctic sea ice cover and the North Atlantic Oscillation. While no clear trend is 
found in the NAO index, the spatial structure of the NAO pattern appears sensitive to the location of the ice loss. We find that the sea ice loss in the Pacific region of the Arctic tends to shift the northern center of action of the NAO eastward, while the sea ice loss in the Atlantic region causes a westward shift. Clarification of the exact mechanism behind this link will require further investigation.

Acknowledgments. The authors thank Ken Caldeira for invaluable suggestions for the experiments and analysis. We are grateful to the Department of Global Ecology at the Carnegie Institution for Science in Stanford, California, for hosting R. Pedersen and facilitating this research, and to the Center for Computational Earth and Environmental Science at Stanford University for providing the computational resources required for this project. The research leading to these results has received funding from the European Research Council under the European Union's Seventh Framework Programme (FP7/20072013)/ERC Grant Agreement 610055 as part of the ice2ice project. The authors acknowledge the support of the Danish National Research Foundation through the Centre for Ice and Climate at the Niels Bohr Institute. We thank the editor and three anonymous reviewers for insightful suggestions that helped improve the manuscript.

\section{REFERENCES}

Bader, J., M. D. S. Mesquita, K. I. Hodges, N. Keenlyside, S. Østerhus, and M. Miles, 2011: A review on Northern Hemisphere sea-ice, storminess and the North Atlantic Oscillation: Observations and projected changes. Atmos. Res., 101, 809-834, doi:10.1016/j.atmosres.2011.04.007.

Barnes, E. A., 2013: Revisiting the evidence linking Arctic amplification to extreme weather in midlatitudes. Geophys. Res. Lett., 40, 4734-4739, doi:10.1002/grl.50880.

Barton, N. P., S. A. Klein, and J. S. Boyle, 2014: On the contribution of longwave radiation to global climate model biases in Arctic lower tropospheric stability. J. Climate, 27, 7250-7269, doi:10.1175/JCLI-D-14-00126.1.

Blüthgen, J., R. Gerdes, and M. Werner, 2012: Atmospheric response to the extreme Arctic sea ice conditions in 2007. Geophys. Res. Lett., 39, L02707, doi:10.1029/2011GL050486.

Boé, J., A. Hall, and X. Qu, 2009: Current GCMs' unrealistic negative feedback in the Arctic. J. Climate, 22, 4682-4695, doi:10.1175/2009JCLI2885.1.

Caldeira, K., and I. Cvijanovic, 2014: Estimating the contribution of sea ice response to climate sensitivity in a climate model. J. Climate, 27, 8597-8607, doi:10.1175/JCLI-D-14-00042.1.

Chiang, J. C. H., and C. M. Bitz, 2005: Influence of high latitude ice cover on the marine intertropical convergence zone. Climate Dyn., 25, 477-496, doi:10.1007/s00382-005-0040-5.

Cohen, J., J. Jones, J. C. Furtado, and E. Tziperman, 2013: Warm Arctic, cold continents: A common pattern related to Arctic sea ice melt, snow advance, and extreme winter weather. Oceanography, 26, 150-160, doi:10.5670/oceanog.2013.70.

Cvijanovic, I., and J. C. H. Chiang, 2013: Global energy budget changes to high latitude North Atlantic cooling and the tropical ITCZ response. Climate Dyn., 40, 1435-1452, doi:10.1007/ s00382-012-1482-1.

— , and K. Caldeira, 2015: Atmospheric impacts of sea ice decline in CO2 induced global warming. Climate Dyn., 44, 1173-1186, doi:10.1007/s00382-015-2489-1.

Danabasoglu, G., and P. R. Gent, 2009: Equilibrium climate sensitivity: Is it accurate to use a slab ocean model? J. Climate, 22 , 2494-2499, doi:10.1175/2008JCLI2596.1.

Deser, C., 2000: On the teleconnectivity of the "Arctic Oscillation." Geophys. Res. Lett., 27, 779-782, doi:10.1029/ 1999GL010945.

—_, G. Magnusdottir, R. Saravanan, and A. Phillips, 2004: The effects of North Atlantic SST and sea ice anomalies on the winter circulation in CCM3. Part II: Direct and indirect components of the response. J. Climate, 17, 877-889, doi:10.1175/1520-0442(2004)017<0877:TEONAS >2.0.CO;2.

- R. Tomas, M. A. Alexander, and D. Lawrence, 2010: The seasonal atmospheric response to projected Arctic sea ice loss in the late twenty-first century. J. Climate, 23, 333-351, doi:10.1175/2009JCLI3053.1.

Dong, B., R. T. Sutton, and T. Woollings, 2011: Changes of interannual NAO variability in response to greenhouse gases forcing. Climate Dyn., 37, 1621-1641, doi:10.1007/ s00382-010-0936-6.

Efron, B., and G. Gong, 1983: A leisurely look at the bootstrap, the jackknife, and cross-validation. Amer. Stat., 37, 36-48.

Francis, J. A., and S. J. Vavrus, 2012: Evidence linking Arctic amplification to extreme weather in mid-latitudes. Geophys. Res. Lett., 39, L06801, doi:10.1029/2012GL051000.

Gent, P. R., and Coauthors, 2011: The Community Climate System Model version 4. J. Climate, 24, 4973-4991, doi:10.1175/ 2011JCLI4083.1.

Greeves, C. Z., V. D. Pope, R. A. Stratton, and G. M. Martin, 2007: Representation of Northern Hemisphere winter storm tracks in climate models. Climate Dyn., 28, 683-702, doi:10.1007/ s00382-006-0205-x.

Hilmer, M., and T. Jung, 2000: Evidence for a recent change in the link between the North Atlantic Oscillation and Arctic sea ice export. Geophys. Res. Lett., 27, 989-992, doi:10.1029/ 1999GL010944.

Hu, Z. Z., and Z. Wu, 2004: The intensification and shift of the annual North Atlantic Oscillation in a global warming scenario simulation. Tellus, 56A, 112-124, doi:10.1111/ j.1600-0870.2004.00050.x.

Hurrell, J. W., 1995: Decadal trends in the North Atlantic Oscillation: Regional temperatures and precipitation. Science, $\mathbf{2 6 9}$, 676-679, doi:10.1126/science.269.5224.676.

— , and C. Deser, 2010: North Atlantic climate variability: The role of the North Atlantic Oscillation. J. Mar. Syst., 79, 231244, doi:10.1016/j.jmarsys.2009.11.002.

— J. J. Hack, B. A. Boville, D. L. Williamson, and J. T. Kiehl, 1998: The dynamical simulation of the NCAR Community Climate Model version 3 (CCM3). J. Climate, 11, 1207-1236, doi:10.1175/1520-0442(1998)011<1207:TDSOTN>2.0.CO;2.

_- Y. Kushnir, G. Ottersen, and M. Visbeck, 2003: An overview of the North Atlantic Oscillation. The North Atlantic Oscillation: Climatic Significance and Environmental Impact, Geophys. Monogr., Vol. 134, Amer. Geophys. Union, $1-35$. 
— - and Coauthors, 2015: The climate data guide: Hurrell North Atlantic Oscillation (NAO) index (PC-based). Accessed 25 March 2015. [Available online at https://climatedataguide.ucar.edu/ climate-data/hurrell-north-atlantic-oscillation-nao-index-pc-based.]

Jaiser, R., K. Dethloff, D. Handorf, A. Rinke, and J. Cohen, 2012: Impact of sea ice cover changes on the Northern Hemisphere atmospheric winter circulation. Tellus, 64A, 11595, doi:10.3402/ tellusa.v64i0.11595.

Jung, T., M. Hilmer, E. Ruprecht, S. Kleppek, S. K. Gulev, and O. Zolina, 2003: Characteristics of the recent eastward shift of interannual NAO variability. J. Climate, 16, 3371-3382, doi:10.1175/1520-0442(2003)016<3371:COTRES >2.0.CO;2.

Kay, J. E., M. M. Holland, C. M. Bitz, E. Blanchard-Wrigglesworth, A. Gettelman, A. Conley, and D. A. Bailey, 2012: The influence of local feedbacks and northward heat transport on the equilibrium Arctic climate response to increased greenhouse gas forcing. J. Climate, 25, 5433-5450, doi:10.1175/ JCLI-D-11-00622.1.

Kutzbach, J. E., 1970: Large-scale features of monthly mean Northern Hemisphere anomaly maps of sea-level pressure. Mon Wea. Rev., 98, 708-716, doi:10.1175/1520-0493(1970)098<0708: $\mathrm{LSFOMM}>2.3 . \mathrm{CO} ; 2$.

Kvamst $\varnothing$, N. G., P. Skeie, and D. B. Stephenson, 2004: Impact of Labrador sea-ice extent on the North Atlantic Oscillation. Int. J. Climatol., 24, 603-612, doi:10.1002/joc.1015.

Lawrence, D. M., and Coauthors, 2011: Parameterization improvements and functional and structural advances in version 4 of the Community Land Model. J. Adv. Model. Earth Syst., 3 , M03001, doi:10.1029/2011MS000045.

Li, C., and D. S. Battisti, 2008: Reduced Atlantic storminess during last glacial maximum: Evidence from a coupled climate model. J. Climate, 21, 3561-3579, doi:10.1175/2007JCLI2166.1.

Magnusdottir, G., C. Deser, and R. Saravanan, 2004: The effects of North Atlantic SST and sea ice anomalies on the winter circulation in CCM3. Part I: Main features and storm track characteristics of the response. J. Climate, 17, 857-876, doi:10.1175/1520-0442(2004)017<0857:TEONAS >2.0.CO;2.

Meier, W., F. Fetterer, M. Savoie, S. Mallory, R. Duerr, and J. C. Stroeve, 2013: NOAA/NSIDC climate data record of passive microwave sea ice concentration, version 2. National Snow and Ice Data Center, accessed 8 July 2015, doi:10.7265/ N55M63M1.

Neale, R. B., and Coauthors, 2010: Description of the NCAR Community Atmosphere Model (CAM 4.0). NCAR Tech. Note NCAR/ TN-485+STR, 212 pp. [Available online at http://www.cesm.ucar. edu/models/ccsm4.0/cam/docs/description/cam4_desc.pdf.]

_ J. Richter, S. Park, P. H. Lauritzen, S. J. Vavrus, P. J. Rasch, and M. Zhang, 2013: The mean climate of the Community Atmosphere Model (CAM4) in forced SST and fully coupled experiments. J. Climate, 26, 5150-5168, doi:10.1175/ JCLI-D-12-00236.1.

Outten, S. D., and I. Esau, 2012: A link between Arctic sea ice and recent cooling trends over Eurasia. Climatic Change, 110, 1069-1075, doi:10.1007/s10584-011-0334-Z.

Peings, Y., and G. Magnusdottir, 2014: Response of the wintertime Northern Hemisphere atmospheric circulation to current and projected Arctic sea ice decline: A numerical study with CAM5. J. Climate, 27, 244-264, doi:10.1175/JCLI-D-13-00272.1.

Peixóto, J. P., and A. H. Oort, 1984: Physics of climate. Rev. Mod. Phys., 56, 365, doi:10.1103/RevModPhys.56.365.

Peterson, K. A., J. Lu, and R. J. Greatbatch, 2003: Evidence of nonlinear dynamics in the eastward shift of the NAO. Geophys. Res. Lett., 30, 1030, doi:10.1029/2002GL015585.
Petoukhov, V., and V. A. Semenov, 2010: A link between reduced Barents-Kara sea ice and cold winter extremes over northern continents. J. Geophys. Res., 115, D21111, doi:10.1029/ 2009JD013568.

Rinke, A., K. Dethloff, W. Dorn, D. Handorf, and J. C. Moore, 2013: Simulated Arctic atmospheric feedbacks associated with late summer sea ice anomalies. J. Geophys. Res. Atmos., 118, 7698-7714, doi:10.1002/jgrd.50584.

Screen, J. A., and I. Simmonds, 2010: The central role of diminishing sea ice in recent Arctic temperature amplification. Nature, 464, 1334-1337, doi:10.1038/nature09051.

— , and _- 2013: Exploring links between Arctic amplification and mid-latitude weather. Geophys. Res. Lett., 40, 959-964, doi:10.1002/grl.50174.

, - C C. Deser, and R. Tomas, 2013: The atmospheric response to three decades of observed Arctic sea ice loss. J. Climate, 26, 1230-1248, doi:10.1175/JCLI-D-12-00063.1.

Seierstad, I. A., and J. Bader, 2009: Impact of a projected future Arctic sea ice reduction on extratropical storminess and the NAO. Climate Dyn., 33, 937-943, doi:10.1007/ s00382-008-0463-x.

Serreze, M. C., and R. G. Barry, 2011: Processes and impacts of Arctic amplification: A research synthesis. Global Planet. Change, 77, 85-96, doi:10.1016/j.gloplacha.2011.03.004.

_ A. P. Barrett, J. C. Stroeve, D. N. Kindig, and M. M. Holland, 2009: The emergence of surface-based Arctic amplification. Cryosphere, 3, 11-19, doi:10.5194/tc-3-11-2009.

,-- , and J. J. Cassano, 2011: Circulation and surface controls on the lower tropospheric air temperature field of the Arctic. J. Geophys. Res., 116, D07104, doi:10.1029/ 2010JD015127.

Sewall, J. O., 2005: Precipitation shifts over western North America as a result of declining arctic sea ice cover: The coupled system response. Earth Interact., 9, 1-23, doi:10.1175/EI171.1.

Stroeve, J. C., V. M. Kattsov, A. P. Barrett, M. C. Serreze, T. Pavlova, M. M. Holland, and W. N. Meier, 2012a: Trends in Arctic sea ice extent from CMIP5, CMIP3 and observations. Geophys. Res. Lett., 39, L16502, doi:10.1029/2012GL052676.

_- M. C. Serreze, M. M. Holland, J. E. Kay, J. Malanik, and A. P. Barrett, 2012b: The Arctic's rapidly shrinking sea ice cover: A research synthesis. Climatic Change, 110, 1005-1027, doi:10.1007/s10584-011-0101-1.

Strong, C., and G. Magnusdottir, 2011: Dependence of NAO variability on coupling with sea ice. Climate Dyn., 36, 1681-1689, doi:10.1007/s00382-010-0752-z.

Tang, Q., X. Zhang, X. Yang, and J. A. Francis, 2013: Cold winter extremes in northern continents linked to Arctic sea ice loss. Environ. Res. Lett., 8, 014036, doi:10.1088/1748-9326/8/1/ 014036.

Ulbrich, U., and M. Christoph, 1999: A shift of the NAO and increasing storm track activity over Europe due to anthropogenic greenhouse gas forcing. Climate Dyn., 15, 551-559, doi: $10.1007 / \mathrm{s} 003820050299$.

Vaughan, D. G., and Coauthors, 2013: Observations: Cryosphere. Climate Change 2013: The Physical Science Basis, T.F. Stocker et al., Eds., Cambridge University Press, 317-382. [Available online at https://www.ipcc.ch/pdf/assessment-report/ar5/wg1/ WG1AR5_Chapter04_FINAL.pdf.]

Vihma, T., 2014: Effects of Arctic sea ice decline on weather and climate: A review. Surv. Geophys., 35, 1175-1214, doi:10.1007/ s10712-014-9284-0.

von Storch, H., and F. W. Zwiers, 2001: Statistical Analysis in Climate Research. Cambridge University Press, 494 pp. 
Wallace, J. M., I. M. Held, D. W. J. Thompson, K. E. Trenberth, and J. E. Walsh, 2014: Global Warming and Winter Weather. Science, 343, 729-730, doi:10.1126/science.343.6172.729.

Wang, Y.-H., G. Magnusdottir, H. Stern, X. Tian, and Y. Yu, 2014: Uncertainty estimates of the EOF-derived North Atlantic Oscillation. J. Climate, 27, 1290-1301, doi:10.1175/ JCLI-D-13-00230.1.

Wanner, H., S. Brönnimann, C. Casty, D. Gyalistras, J. Luterbacher, C. Schmutz, D. B. Stephenson, and E. Xoplaki,
2001: North Atlantic Oscillation-concepts and studies. Surv. Geophys., 22, 321-381, doi:10.1023/A:1014217317898.

Yang, S., and J. H. Christensen, 2012: Arctic sea ice reduction and European cold winters in CMIP5 climate change experiments. Geophys. Res. Lett., 39, L20707, doi:10.1029/2012GL053338.

Zhang, Y., D. J. Seidel, J.-C. Golaz, C. Deser, and R. A. Tomas, 2011: Climatological characteristics of Arctic and Antarctic surface-based inversions. J. Climate, 24, 5167-5186, doi:10.1175/2011JCLI4004.1. 